\title{
Simulating Molecular Interactions of Carbon Nanoparticles with a Double-Stranded DNA Fragment
}

\author{
Zhuang Wang, ${ }^{1}$ Hao Fang, ${ }^{1}$ Se Wang, ${ }^{1}$ Fan Zhang, ${ }^{1}$ and Degao Wang ${ }^{2}$ \\ ${ }^{1}$ Jiangsu Key Laboratory of Atmospheric Environment Monitoring and Pollution Control (AEMPC), Collaborative Innovation \\ Center of Atmospheric Environment and Equipment Technology (AEET), Jiangsu Engineering Technology Research Centre \\ of Environmental Cleaning Materials (ECM), School of Environmental Science and Engineering, Nanjing University of Information \\ Science and Technology, Nanjing 210044, China \\ ${ }^{2}$ Environmental Science and Engineering College, Dalian Maritime University, Dalian 116026, China
}

Correspondence should be addressed to Zhuang Wang; zhuang.wang@nuist.edu.cn

Received 29 April 2015; Revised 17 September 2015; Accepted 20 September 2015

Academic Editor: Maria N. D. S. Cordeiro

Copyright (C) 2015 Zhuang Wang et al. This is an open access article distributed under the Creative Commons Attribution License, which permits unrestricted use, distribution, and reproduction in any medium, provided the original work is properly cited.

\begin{abstract}
Molecular interactions between carbon nanoparticles (CNPs) and a double-stranded deoxyribonucleic acid (dsDNA) fragment were investigated using molecular dynamics (MD) simulations. Six types of CNPs including fullerenes $\left(C_{60}\right.$ and $\left.C_{70}\right)$, $(8,0)$ single-walled carbon nanotube (SWNT), $(8,0)$ double-walled carbon nanotube (DWNT), graphene quantum dot (GQD), and graphene oxide quantum dot (GOQD) were studied. Analysis of the best geometry indicates that the dsDNA fragment can bind to CNPs through pi-stacking and T-shape. Moreover, $\mathrm{C}_{60}$, DWNT, and GOQD bind to the dsDNA molecules at the minor groove of the nucleotide, and $\mathrm{C}_{70}$, SWNT, and GQD bind to the dsDNA molecules at the hydrophobic ends. Estimated interaction energy implies that van der Waals force may mainly contribute to the mechanisms for the dsDNA-C ${ }_{60}$, dsDNA- $\mathrm{C}_{70}$, and dsDNASWNT interactions and electrostatic force may contribute considerably to the dsDNA-DWNT, dsDNA-GQD, and dsDNA-GOQD interactions. On the basis of the results from large-scale MD simulations, it was found that the presence of the dsDNA enhances the dispersion of $\mathrm{C}_{60}, \mathrm{C}_{70}$, and SWNT in water and has a slight impact on DWNT, GQD, and GOQD.
\end{abstract}

\section{Introduction}

Carbon-based nanomaterials (CNMs) have attracted special attention owing to their excellent properties, for example, mechanical properties, electric characteristics, chemical quality, and large specific area [1]. Various CNMs have been extensively investigated since the discovery of fullerenes $\left(\mathrm{C}_{60} / \mathrm{C}_{70}\right)$, carbon nanotubes, graphene, and graphene oxide [2]. The huge application potentials of CNMs in diverse areas have strongly stimulated their production and consumption [3]. Inevitably, carbon nanoparticles (CNPs) have come into both environment and biological systems [4] and incurred potential environmental and ecological risks [5]. Thus, the related behavior and effect of CNPs in environmental and biological systems need to be urgently estimated.

There are an endless number of natural biomacromolecules in the environment. Adsorption of these biomacromolecules can occur in all environments [4].
On uptake by biological organisms, due to their strong adsorptive ability CNPs may be subjected to alterations through interactions with biomacromolecules (e.g., deoxyribonucleic acid, DNA) [4, 6-8]. It is known that DNA is a naturally occurring polymer which plays a central role in biology [9]. For the case of the interaction Pang et al. [10] found that $\mathrm{C}_{60}$ molecule can interact strongly with a double-stranded deoxyribonucleic acid (dsDNA) molecule. Bonanni and Pumera [11] found that DNA is assembled onto graphene surface by physical adsorption. Lei et al. [12] also found that dsDNA can bind to graphene oxide spontaneously and form a complex. Despite its relevance, understanding the mechanism of the DNA-CNP interaction is still elusive.

Moreover, several authors noticed that adsorption of biomacromolecules can affect nanoparticle aggregation, dissolution, uptake, and biodistribution [4]. For the case of the DNA-CNP interaction Zheng et al. [9] found SWNTs are effectively dispersed in water by their sonication in 

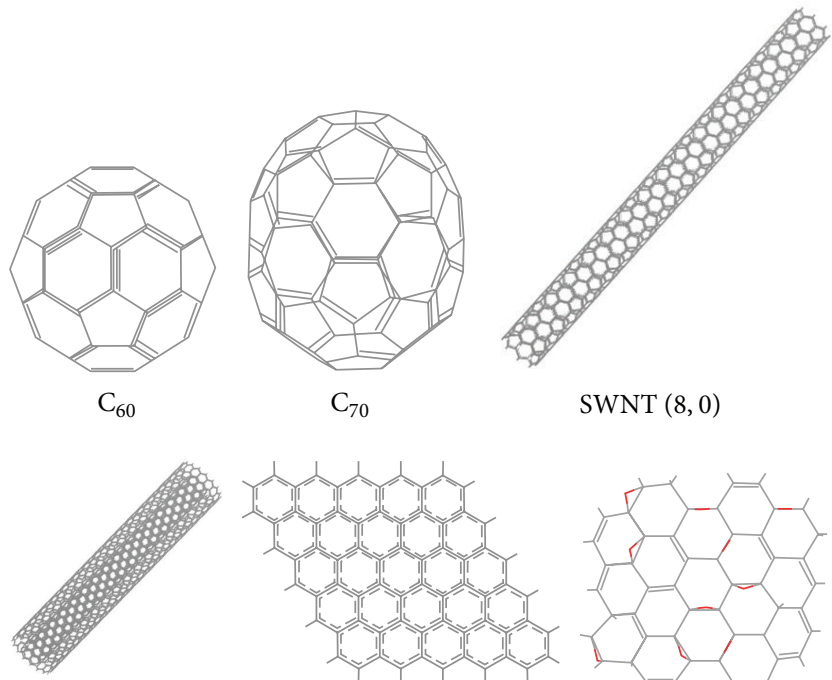

$\operatorname{DWNT}(8,0)$

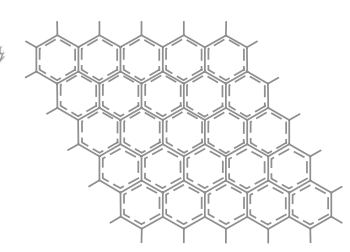

GQD

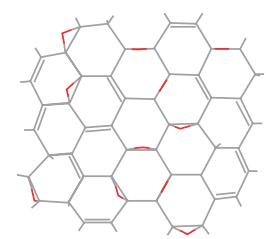

GOQD
FIGURE 1: Schematic diagram showing the studied carbon nanoparticles.

the presence of single-stranded DNA (ssDNA). Nakashima et al. [13] also found that DNA molecules dissolve SWNTs in aqueous solution. However, comprehensive experimental mapping of CNP aqueous behavior for the large number of present and anticipated emerging $\mathrm{CNMs}$ is a daunting and possibly impractical task. To date, molecular simulation has emerged as a promising and powerful tool that can effectively probe the interaction mechanism of organic molecules upon the surface of CNPs [14-17]. Therefore, more studies are needed to probe the potential adsorption and dispersion behaviors of CNPs in the presence of biomacromolecules at a molecular level.

In this paper, we present the results of molecular simulations on interactions between six types of CNPs and a dsDNA fragment, obtained by using molecular dynamics (MD) simulations. Optimum geometry and interaction energy $\left(E_{\text {int }}\right)$ of the CNPs with the dsDNA fragment were carried out to explore the interaction mechanism. Besides providing the interaction mechanisms, the present study also described the aqueous dispersion process of the CNP aggregates in the presence of the dsDNA fragment by means of a large-scale MD simulation.

\section{Computational Methods}

2.1. Annealing Simulations. Six representative CNPs, that is, $\mathrm{C}_{60}, \mathrm{C}_{70}$, single-walled carbon nanotube (SWNT), doublewalled carbon nanotube (DWNT), graphene, and graphene oxide, as well as a dsDNA fragment, were selected as model molecules (Figure 1). The constructed adsorbents included a SWNT $(8,0)$, DWNT $(8,0)$, and graphene quantum dot (GQD), which are composed of 512, 1600, and 70 carbon atoms and 16, 50, and 22 saturated hydrogen atoms, respectively. A graphene oxide quantum dot (GOQD) consists of 50 carbon atoms, 11 oxygen atoms, and 24 saturated hydrogen atoms.

To search for the best geometry for each dsDNA-CNP complex, a classical annealing simulation was carried out using the Forcite Plus code [18]. The universal force field was adopted to perform this simulation. The cutoff radius was chosen to be $18.5 \AA$. The annealing simulation was performed as follows: a total of 200 annealing cycles were simulated with an initial temperature of $200 \mathrm{~K}$, a midcycle temperature of $300 \mathrm{~K}$, and 50 heating ramps per cycle, with 100 dynamic steps per ramp. The canonical ensemble (NVT ensemble, in which the number of molecules $[N]$, volume $[V]$, and temperature of the system $[T]$ are kept constant) was used and the MD simulations were performed with a time step of $1.0 \mathrm{fs}$ and a Nosé thermostat. After each cycle, the lowest energy configuration was optimized. van der Waals, electrostatic, and total potential energies of the studied systems were calculated using the annealing simulation.

For the interaction systems, $E_{\text {int }}$ is used to evaluate the stability of the dsDNA-CNPs complexes. The magnitude of $E_{\text {int }}$ is an indication of the magnitude of the driving force towards complexation. A negative $E_{\text {int }}$ value corresponded to a stable adsorption on the CNMs. $E_{\text {int }}$ was calculated by

$$
E_{\text {int }}=E_{\mathrm{dsDNA}-\mathrm{CNP}}-E_{\mathrm{dsDNA}}-E_{\mathrm{CNP}},
$$

where $E_{\mathrm{dsDNA}-\mathrm{CNP}}, E_{\mathrm{dsDNA}}$, and $E_{\mathrm{CNP}}$ represent the energies (van der Waals, electrostatic, or total potential energies) of the complex, the individual dsDNA, and the isolated CNP, respectively.

2.2. MD Simulations. Aqueous dispersion processes of CNP agglomerate in the presence of the dsDNA fragment were modeled by full atomistic MD simulations in NVT ensemble using the universal force field, subjected to periodic boundary conditions in all three directions. The initial configuration of each system consists of an agglomerate species of the CNPs. For the $\left[\mathrm{CNP}+\mathrm{H}_{2} \mathrm{O}\right]$ binary system, $900 \mathrm{SPC} / \mathrm{E}$ [19] water molecules were incorporated in each unit cell. For the [CNP $+\mathrm{dsDNA}+\mathrm{H}_{2} \mathrm{O}$ ] ternary system, one dsDNA molecular and 900 SPC/E water molecules were incorporated in each unit cell. Our MD simulations were performed at the temperature of 298 K. 100000 simulation steps were carried out to relax the system into equilibrium at a time step of $0.1 \mathrm{fs}$ and the final one 10 ps for production.

The mean square displacement (MSD) that describes the average displacement of an atom during a fixed time $t$ was employed to characterize the dispersion process of the CNPs in the $\left[\mathrm{CNP}+\mathrm{H}_{2} \mathrm{O}\right]$ binary system and $[\mathrm{CNP}+\mathrm{dsDNA}+$ $\mathrm{H}_{2} \mathrm{O}$ ] ternary system. The MSD for each CNP in the studied systems was calculated by preparing several time series data items of length $t$, averaging those data items, and averaging those data items based on the number of atoms $(N)$; then MSD is defined as follows:

$$
\begin{aligned}
\operatorname{MSD} & =\left\langle|r(t)-r(0)|^{2}\right\rangle \\
& =\frac{1}{N M} \sum_{i}^{N} \sum_{k}^{M}\left|r_{i}\left(t_{k}+t\right)-r_{i}\left(t_{k}\right)\right|^{2},
\end{aligned}
$$




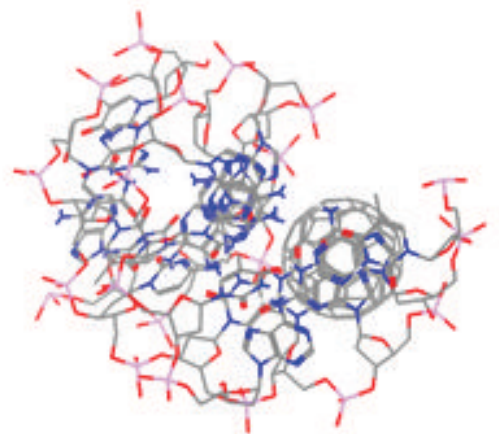

dsDNA- $\mathrm{C}_{60}$

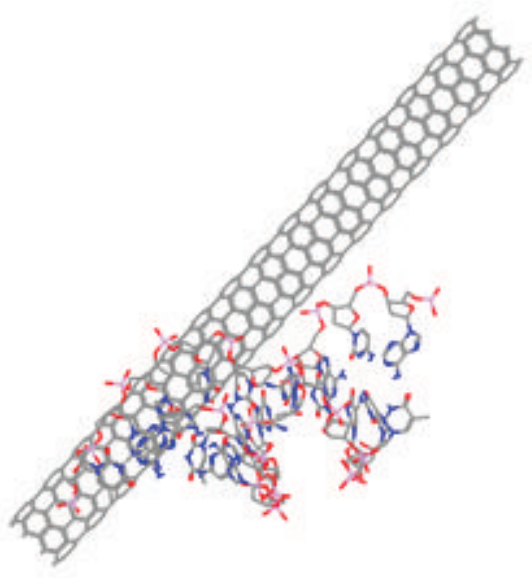

dsDNA-SWNT $(8,0)$

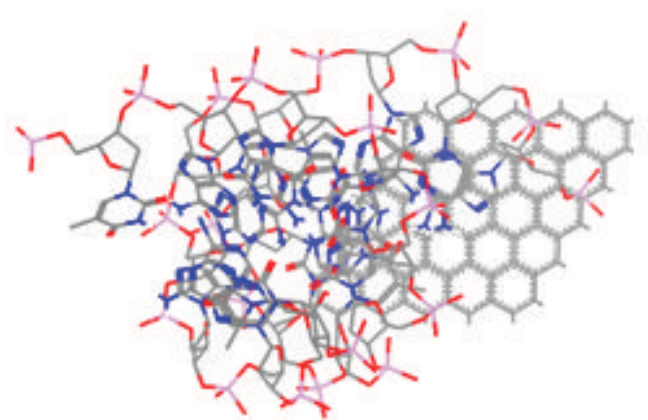

dsDNA-GQD

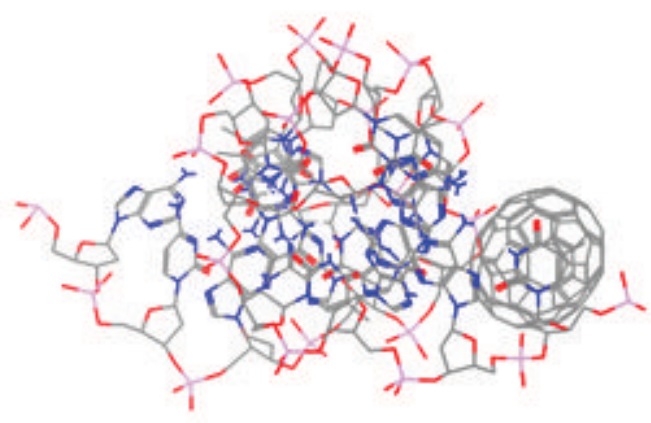

dsDNA- $\mathrm{C}_{70}$

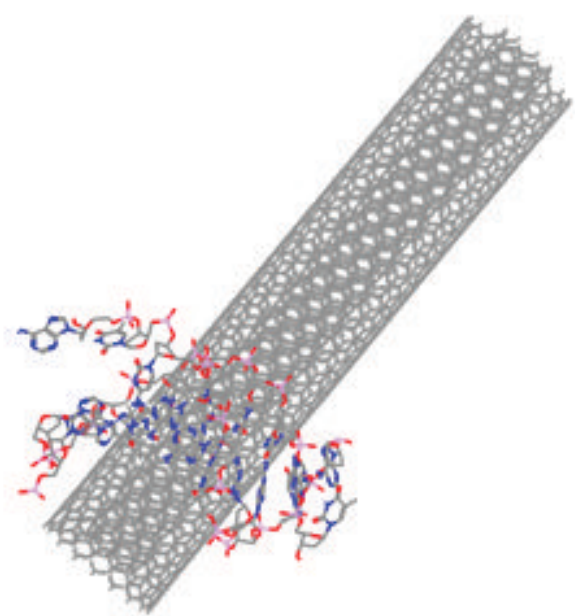

dsDNA-DWNT $(8,0)$

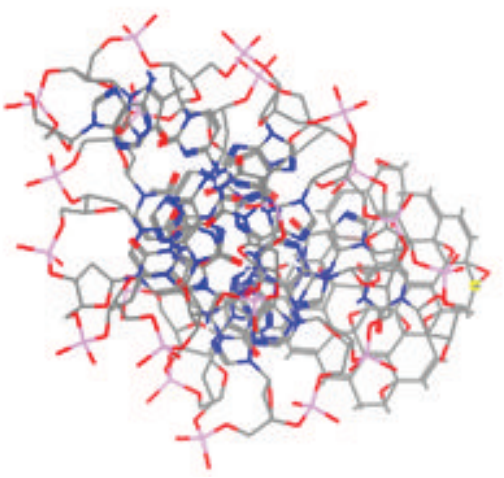

dsDNA-GOQD

Figure 2: Optimized structures of the dsDNA-CNP complexes.

where $M$ is the number of time series data and $t_{k}$ is the starting time of $k$ th time series data. The self-diffusion coefficient $(D)$ was calculated from Einstein's equation as follows:

$$
D=\frac{1}{6 t} \text { MSD. }
$$

All the simulation parameters for each structure studied are shown in Table 1. The large-scale MD simulations were carried out by using Material Explorer (Version 5.0).

\section{Results and Discussion}

3.1. Features of the Interaction between the dsDNA and the CNPs. The optimized conformations obtained after the annealing simulation are shown in Figure 2. The optimized geometries for the dsDNA on the CNP surface indicate that the dsDNA can bind to the CNPs through pi-stacking and T-shape. Zheng et al. [9] also found that the $\pi$-type of interaction contributes to the ssDNA-assisted dispersion and separation of SWNT. In addition, it was also found that the $\mathrm{C}_{60}$, DWNT, and GOQD bind to the dsDNA molecules at 

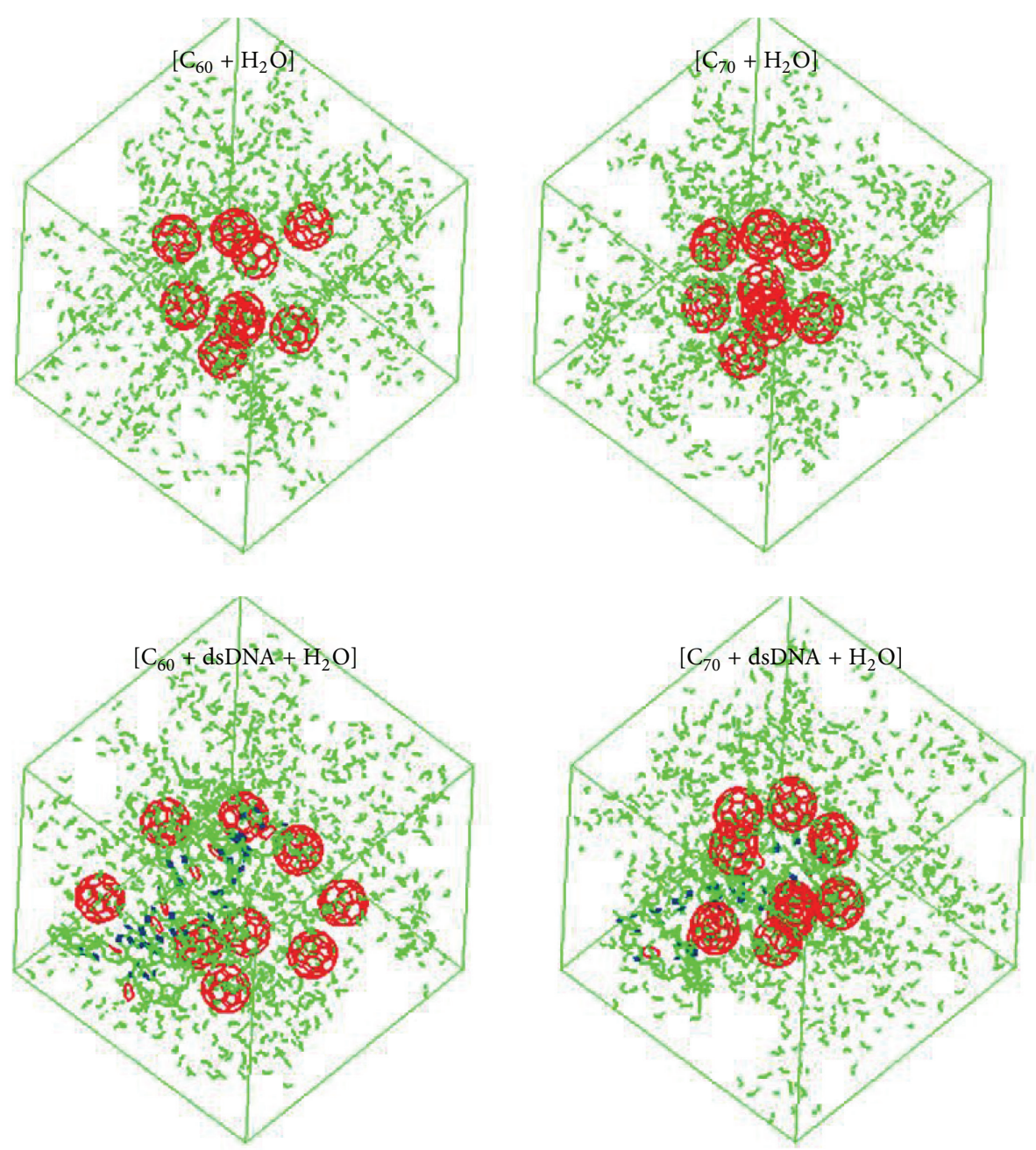

Figure 3: Perspective snapshot for the dispersion state of the fullerene agglomerate in the [fullerene $+\mathrm{H}_{2} \mathrm{O}$ ] binary systems and [fullerene + dsDNA $+\mathrm{H}_{2} \mathrm{O}$ ] ternary systems after 100000 simulation steps.

TABLE 1: List of the simulation parameters.

\begin{tabular}{lcc}
\hline Number & Symbol & Description \\
\hline 1 & TPE & Total potential energy \\
2 & VWE & van der Waals energy \\
3 & EE & Electrostatic energy \\
4 & $D$ & Self-diffusion coefficient \\
\hline
\end{tabular}

the minor groove of the nucleotide and the $\mathrm{C}_{70}$, SWNT, and GQD bind to the dsDNA molecules at the hydrophobic ends. Previous studies also indicate that $\mathrm{C}_{60}$ can bind with the hydrophobic ends or the minor groove of dsDNA [20, 21].

In order to reveal the mechanisms of the dsDNA-CNP interactions, the interaction energies $\left(E_{\text {int }}\right)$ derived from the van der Waals $\left(E_{\mathrm{v} \text {-int }}\right)$, electrostatic $\left(E_{\mathrm{e} \text {-int }}\right)$, and total potential energies $\left(E_{\mathrm{p} \text {-int }}\right)$ are summarized in Table 2. $E_{\text {int }}$ indicates the strength of the interactions. The computed $E_{\text {int }}$ values are negative, indicating that the CNPs can form stable complexes with the dsDNA molecules. Among these six CNPs, the
DWNT has the highest absolute $E_{\text {p-int }}$ with the dsDNA, which suggests the relatively strong adsorption strength between the DWNT and dsDNA. Generally, the adsorptive affinity of the dsDNA onto the CNPs increases in the order of $\mathrm{C}_{70}<$ GOQD $<$ SWNT $<\mathrm{C}_{60}<\mathrm{GQD}<\mathrm{DWNT}$. Furthermore, as indicated by absolute $E_{\mathrm{v} \text {-int }}$ and $E_{\mathrm{p} \text {-int }}$, the contribution of the van der Waals interaction between the dsDNA and the CNPs increases in the order of GQD (ca. 22\%) < DWNT (ca. 28\%) $<$ GOQD (ca. 46\%) < $\mathrm{C}_{60}$ (ca. 51\%) < SWNT (ca. 61\%) < $\mathrm{C}_{70}$ (ca. 90\%). This implies that the van der Waals interaction considerably contributes to the mechanisms of the dsDNA$\mathrm{C}_{60}$, dsDNA- $\mathrm{C}_{70}$, and dsDNA-SWNT interactions. As indicated by absolute $E_{\mathrm{e} \text {-int }}$ and $E_{\mathrm{p} \text {-int }}$, the contribution of the electrostatic interaction between the dsDNA and the CNPs increases in the order of $\mathrm{C}_{70}$ (ca. 1\%) $<$ SWNT (ca. 26\%) $<\mathrm{C}_{60}($ ca. 36\%) < GOQD (ca. 49\%) < DWNT (ca. 51\%) < GQD (ca. 61\%). This implies that the electrostatic interaction mainly contributes to the mechanisms of the dsDNA-DWNT, dsDNA-GQD, and dsDNA-GOQD interactions. This may be caused by the vertical aromatic rings of the dsDNA molecule 
TABLE 2: Interaction energies $\left(E_{\text {int }}\right)$ of the dsDNA fragment on the surface of the carbon nanoparticles (CNPs).

\begin{tabular}{lccccc}
\hline CNP & van der Waals & $\begin{array}{c}E_{\text {int }}(\mathrm{Kcal} / \mathrm{mol}) \\
\text { Electrostatic }\end{array}$ & Total potential & D $\left[\mathrm{CNPs}+\mathrm{H}_{2} \mathrm{O}\right]$ & $\begin{array}{c}\left.\mathrm{A}^{2} / \mathrm{ps}\right) \\
{\left[\mathrm{CNPs}+\mathrm{dsDNA}+\mathrm{H}_{2} \mathrm{O}\right]}\end{array}$ \\
\hline $\mathrm{C}_{60}$ & -99 & -69 & -193 & 0.26 & 7.30 \\
$\mathrm{C}_{70}$ & -84 & 1.3 & -93 & 0.08 & 0.44 \\
SWNT & -109 & -47 & -178 & 0.05 & 0.07 \\
DWNT & -115 & -208 & -405 & 8.93 & 9.04 \\
GQD & -66 & -127 & -207 & 0.47 & 0.40 \\
GOQD & -51 & -54 & -110 & 0.84 & 0.86 \\
\hline
\end{tabular}

on the CNP surfaces because attractive electrostatics is the most important factor affecting the $\mathrm{T}$-shape configuration [22].

\subsection{Impacts of the dsDNA on Aqueous Dispersion of the CNP} Agglomerate. To evaluate the impacts of the dsDNA on the dispersion of the CNPs in water, the dispersion of the CNP agglomerate in the [CNP $+\mathrm{H}_{2} \mathrm{O}$ ] binary systems and [CNP $+\mathrm{dsDNA}+\mathrm{H}_{2} \mathrm{O}$ ] ternary systems was performed by the large-scale MD simulations. Take $\mathrm{C}_{60}$ and $\mathrm{C}_{70}$; for example, snapshots corresponding to the dispersion state and spatial distribution of the fullerene agglomerate in the [fullerene + $\mathrm{H}_{2} \mathrm{O}$ ] binary systems and [fullerene $+\mathrm{dsDNA}+\mathrm{H}_{2} \mathrm{O}$ ] ternary systems are shown in Figure 3. Obviously, the presence of dsDNA improves the dispersion extent of both $\mathrm{C}_{60}$ and $\mathrm{C}_{70}$ in water. Moreover, the dsDNA has more significant impacts on the aqueous dispersion of $\mathrm{C}_{60}$. Furthermore, the $D$ value was calculated to quantitatively evaluate the dispersion extent of the CNPs in the [CNP $+\mathrm{H}_{2} \mathrm{O}$ ] binary systems and [CNP + dsDNA $+\mathrm{H}_{2} \mathrm{O}$ ] ternary systems (Table 2 ). The $D$ value of $\mathrm{C}_{60}$ in the $\left[\mathrm{C}_{60}+\mathrm{dsDNA}+\mathrm{H}_{2} \mathrm{O}\right]$ ternary systems is approximately 24.3 times more than that in the $\left[\mathrm{C}_{60}+\mathrm{H}_{2} \mathrm{O}\right]$ binary systems. The $D$ value of $\mathrm{C}_{70}$ in the $\left[\mathrm{C}_{70}+\mathrm{dsDNA}+\right.$ $\mathrm{H}_{2} \mathrm{O}$ ] ternary systems is approximately 5.5 times more than that in the $\left[\mathrm{C}_{70}+\mathrm{H}_{2} \mathrm{O}\right]$ binary systems. Therefore, the $D$ analysis also indicates that the dsDNA influences the aqueous dispersion of $\mathrm{C}_{60}$ more than $\mathrm{C}_{70}$. This also implies that the presence of the dsDNA significantly enhances the aqueous dispersion of the fullerenes. For the SWNT, the observed $D$ value in the [SWNT + dsDNA $+\mathrm{H}_{2} \mathrm{O}$ ] ternary systems has a difference of $29 \%$ to the $D$ value in the [SWNT $+\mathrm{H}_{2} \mathrm{O}$ ] binary systems, suggesting that the dsDNA moderately increases the aqueous dispersion of SWNT. Nakashima et al. [13] also found that DNA molecules can dissolve SWNTs in an aqueous solution by transmission electron microscopy, atomic force microscopy, and UV-Vis-NIR absorption spectroscopy. However, for the DWNT and GOQD, the computed $D$ values extremely approach the observed values. This means that the dsDNA has a slight impact on the aqueous dispersion of DWNT and GOQD. Moreover, for the GQD, the predicted $D$ value in the $\left[\mathrm{GQD}+\mathrm{dsDNA}+\mathrm{H}_{2} \mathrm{O}\right.$ ] ternary systems is lower than that in the [GQD $+\mathrm{H}_{2} \mathrm{O}$ ] binary systems, indicating that the dsDNA slightly decreases the aqueous dispersion of GQD.

\section{Conclusions}

Through molecular dynamic simulations, we have mainly addressed the molecular interactions between the dsDNA and the six CNPs $\left(\mathrm{C}_{60}, \mathrm{C}_{70}\right.$, SWNT, DWNT, GQD, and GOQD). The optimized conformations obtained show that the dsDNA can bind to the CNPs through pi-stacking and T-shape. Moreover, the $\mathrm{C}_{60}$, DWNT, and GOQD bind to the dsDNA molecules at the minor groove of the nucleotide, and the $\mathrm{C}_{70}$, SWNT, and GQD bind to the dsDNA molecules at the hydrophobic ends. The estimated interaction energy suggests that the van der Waals force may mainly contribute to the molecular mechanism for the dsDNA- $\mathrm{C}_{60}$, dsDNA- $\mathrm{C}_{70}$, and dsDNA-SWNT interactions and the electrostatic force may contribute considerably to the dsDNA-DWNT, dsDNAGQD, and dsDNA-GOQD interactions. The self-diffusion coefficients estimated at different dsDNA-CNP interaction systems indicate that there exist different dispersion states of the CNP agglomerate in the presence of the dsDNA.

\section{Conflict of Interests}

The authors declare that there is no conflict of interests regarding the publication of this paper.

\section{Acknowledgments}

This study was supported by the National Natural Science Foundation of China (Grant no. 21407080), the Foundation Research Project of Jiangsu Province (nos. BK20140987 and BK20150891), and Research Foundation for Advanced Talents (nos. 2241071201134, 2243141501011, and 2241071301059) of Nanjing University of Information Science and Technology. Degao Wang also thanks the support from the Open fund by Jiangsu Key Laboratory of Atmospheric Environment Monitoring and Pollution Control (no. KHK1309), a Project Funded by the Priority Academic Program Development of Jiangsu Higher Education Institutions (PAPD).

\section{References}

[1] H. Wang, S.-T. Yang, A. Cao, and Y. Liu, "Quantification of carbon nanomaterials in vivo," Accounts of Chemical Research, vol. 46, no. 3, pp. 750-760, 2013. 
[2] M. S. Mauter and M. Elimelech, "Environmental applications of carbon-based nanomaterials," Environmental Science and Technology, vol. 42, no. 16, pp. 5843-5859, 2008.

[3] A. Maynard and E. Michelson, The Nanotechnology Consumer Products Inventory, Woodrow Wilson International Center for Scholars, 2006, http://www.nanotechproject.org/ inventories/consumer/.

[4] G. V. Lowry, K. B. Gregory, S. C. Apte, and J. R. Lead, “Transformations of nanomaterials in the environment," Environmental Science and Technology, vol. 46, no. 13, pp. 6893-6899, 2012.

[5] R. H. Hurt, M. Monthioux, and A. Kane, "Toxicology of carbon nanomaterials: status, trends, and perspectives on the special issue," Carbon, vol. 44, no. 6, pp. 1028-1033, 2006.

[6] M. Mahmoudi, I. Lynch, M. R. Ejtehadi, M. P. Monopoli, F. B. Bombelli, and S. Laurent, "Protein-nanoparticle interactions: opportunities and challenges," Chemical Reviews, vol. 111, no. 9, pp. 5610-5637, 2011.

[7] C. C. Ge, J. F. Du, L. Zhao et al., "Binding of blood proteins to carbon nanotubes reduces cytotoxicity," Proceedings of the National Academy of Sciences of the United States of America, vol. 108, no. 41, pp. 16968-16973, 2011.

[8] P. Jin, Y. Chen, S. B. Zhang, and Z. Chen, "Interactions between $\mathrm{Al}_{12} \mathrm{X}(\mathrm{X}=\mathrm{Al}, \mathrm{C}, \mathrm{N}$ and $\mathrm{P})$ nanoparticles and DNA nucleobases/base pairs: implications for nanotoxicity," Journal of Molecular Modeling, vol. 18, no. 2, pp. 559-568, 2012.

[9] M. Zheng, A. Jagota, E. D. Semke et al., "DNA-assisted dispersion and separation of carbon nanotubes," Nature Materials, vol. 2, no. 5, pp. 338-342, 2003.

[10] D. W. Pang, Y. D. Zhao, P. F. Fang et al., "Interactions between DNA and a water-soluble $\mathrm{C}_{60}$ derivative studied by surfacebased electrochemical methods," Journal of Electroanalytical Chemistry, vol. 567, no. 2, pp. 339-349, 2004.

[11] A. Bonanni and M. Pumera, "Graphene platform for hairpinDNA-based impedimetric genosensing," ACS Nano, vol. 5, no. 3, pp. 2356-2361, 2011.

[12] H. Lei, L. Mi, X. Zhou et al., "Adsorption of double-stranded DNA to graphene oxide preventing enzymatic digestion," Nanoscale, vol. 3, no. 9, pp. 3888-3892, 2011.

[13] N. Nakashima, S. Okuzono, H. Murakami, T. Nakai, and K. Yoshikawa, "DNA dissolves single-walled carbon nanotubes in water," Chemistry Letters, vol. 32, no. 5, pp. 456-457, 2003.

[14] W. Qin, X. Li, W.-W. Bian, X.-J. Fan, and J.-Y. Qi, "Density functional theory calculations and molecular dynamics simulations of the adsorption of biomolecules on graphene surfaces," Biomaterials, vol. 31, no. 5, pp. 1007-1016, 2010.

[15] Z. Wang, J. Chen, Q. Sun, and W. J. G. M. Peijnenburg, " $\mathrm{C}_{60}$ DOM interactions and effects on $\mathrm{C}_{60}$ apparent solubility: a molecular mechanics and density functional theory study," Environment International, vol. 37, no. 6, pp. 1078-1082, 2011.

[16] Z. Wang, L. L. Tang, and W. J. G. M. Peijnenburg, “Theoretical investigations on $\mathrm{C}_{60}$-ionic liquid interactions and their impacts on $\mathrm{C}_{60}$ dispersion behavior," Environmental Toxicology and Chemistry, vol. 33, no. 8, pp. 1802-1808, 2014.

[17] Z. Wang, L. L. Tang, and D. Wang, "Impacts of $\mathrm{C}_{60}$-ionic liquids (ILs) interactions and IL alkyl chain length on $\mathrm{C}_{60}$ dispersion behavior: insights at the molecular level," Bulletin of the Korean Chemical Society, vol. 35, no. 9, pp. 2679-2683, 2014.

[18] S. G. Santos, J. V. Santana, F. F. Maia Jr. et al., "Adsorption of ascorbic acid on the $\mathrm{C}_{60}$ fullerene," The Journal of Physical Chemistry B, vol. 112, no. 45, pp. 14267-14272, 2008.
[19] H. J. C. Berendsen, J. R. Grigera, and T. P. Straatsma, "The missing term in effective pair potentials," Journal of Physical Chemistry, vol. 91, no. 24, pp. 6269-6271, 1987.

[20] M. H. Alshehri, B. J. Cox, and J. M. Hill, " ${ }_{60}$ fullerene binding to DNA," The European Physical Journal B, vol. 87, no. 9, pp. 199210, 2014.

[21] X. C. Zhao, A. Striolo, and P. T. Cummings, " $\mathrm{C}_{60}$ binds to and deforms nucleotides," Biophysical Journal, vol. 89, no. 6, pp. 3856-3862, 2005.

[22] G. B. McGaughey, M. Gagné, and A. K. Rappé, “ $\pi$-Stacking interactions. Alive and well in proteins," The Journal of Biological Chemistry, vol. 273, no. 25, pp. 15458-15463, 1998. 

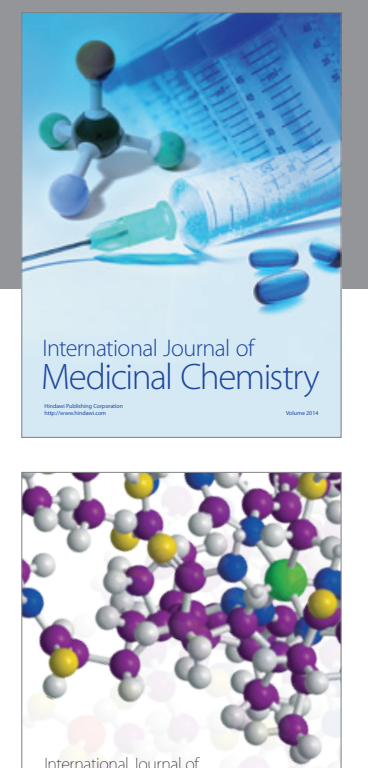

\section{Carbohydrate} Chemistry

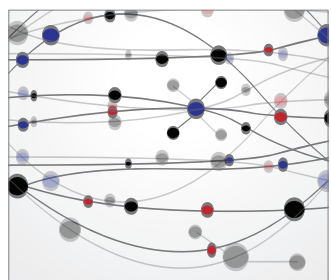

The Scientific World Journal
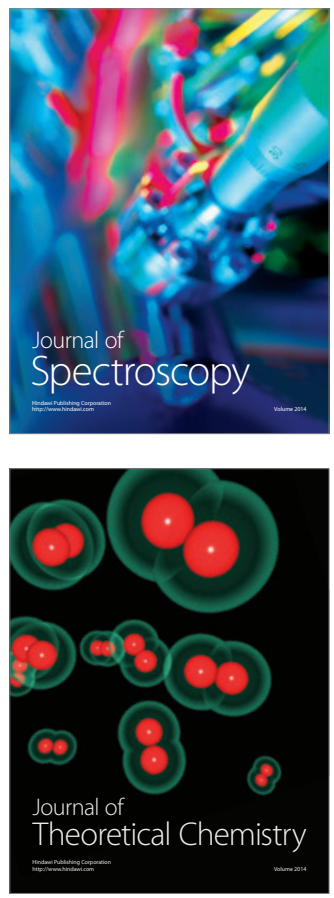
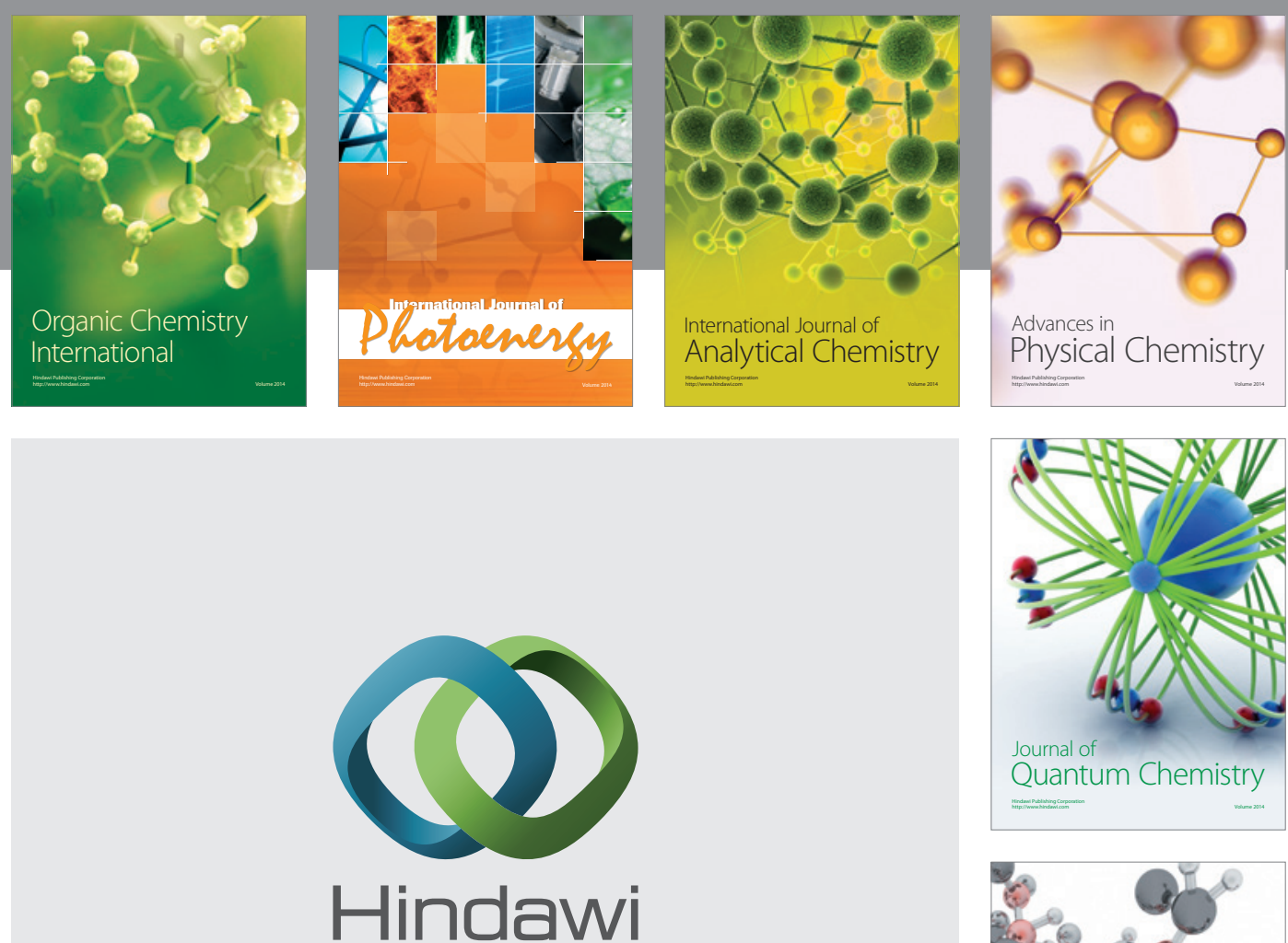

Submit your manuscripts at

http://www.hindawi.com

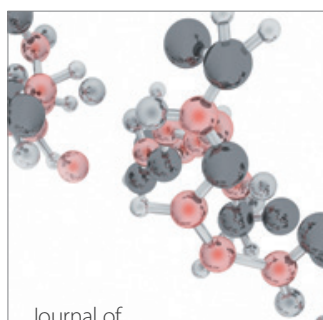

Analytical Methods

in Chemistry

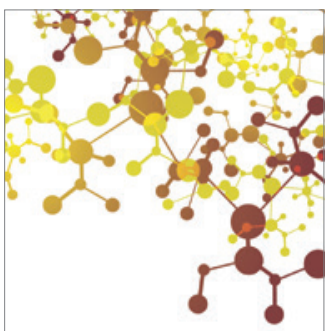

Journal of

Applied Chemistry

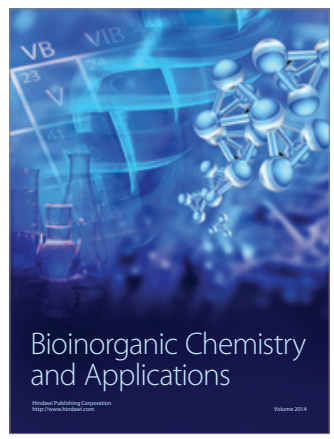

Inorganic Chemistry
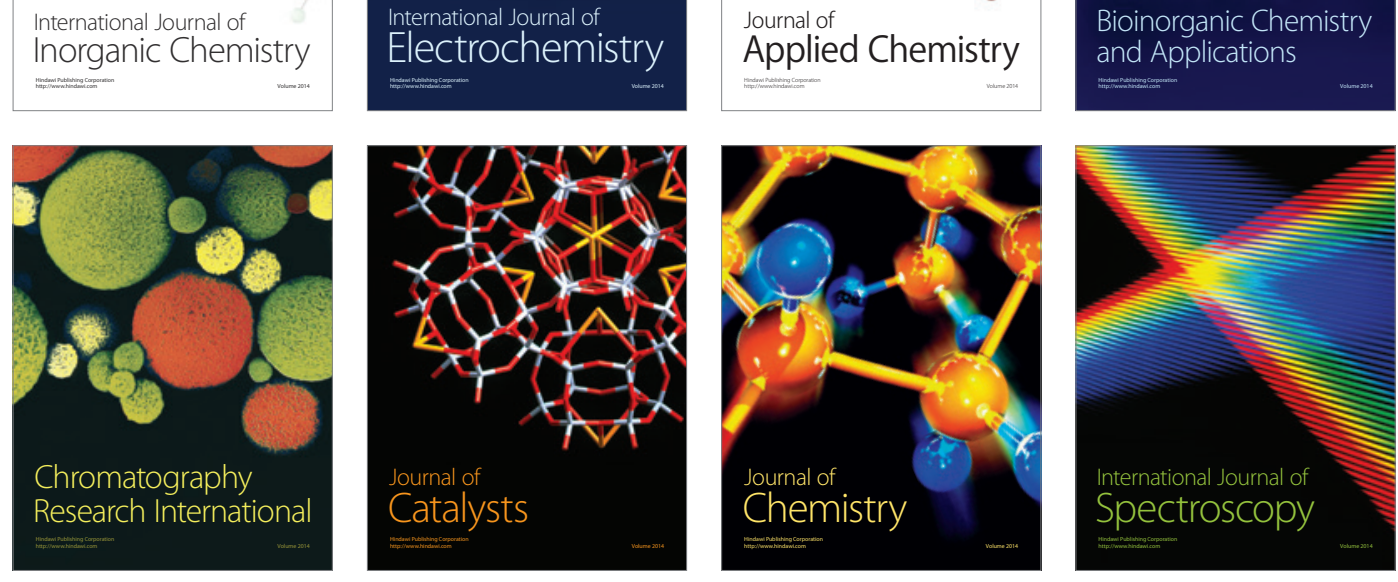